\title{
DOSES DE ÁCIDO GIBERÉLICO NA FRUTIFICAÇÃO EFETIVA E QUALIDADE DE FRUTOS DE ATEMOIEIRA 'GEFNER'
}

\author{
MARLON CRISTIAN TOLEDO PEREIRA², RAYKA KRISTIAN ALVES SANTOS ${ }^{3}$, \\ SILVIA NIETSCHE ${ }^{2}$, GISELE POLETE MIZOBUTSI ${ }^{2}$, EDSON FAGNE DOS SANTOS ${ }^{3}$
}

RESUMO-Este trabalho teve como objetivo avaliar o efeito da aplicação de ácido giberélico $\left(\mathrm{GA}_{3}\right)$ no pegamento, frutificação efetiva e qualidade de frutos de atemoieira 'Gefner', nas condições irrigadas do norte de Minas Gerais. O experimento foi conduzido em pomar comercial de atemoieira 'Gefner', em Matias Cardoso. O delineamento experimental foi o de blocos casualizados, com quatro repetições e cinco frutos por parcela. Os tratamentos utilizados foram diferentes doses do produto comercial Pro-Gibb ${ }^{\circledR}$, composto por $10 \%$ de $\mathrm{GA}_{3}$, na forma de pó solúvel, sendo: 0 (testemunha), 250; 500; 750 e $1.000 \mathrm{mg}^{-\mathrm{L}^{-1}}$. O produto foi aplicado diretamente nas flores de atemoieira, no momento da antese, e repetido nos frutos aos 7; $21 \mathrm{e}$ 35 dias após a antese. Foram avaliados quinzenalmente pegamento, comprimento e diâmetro dos frutos. Após a colheita, as características físico-químicas avaliadas foram submetidas à análise de variância, e os efeitos das doses foram testados e ajustados em equações de regressão. A porcentagem de pegamento e frutificação efetiva dos frutos de atemoieira 'Gefner', a massa de polpa, casca e frutos, e o pH aumentaram com o incremento das doses de $\mathrm{GA}_{3}$. A aplicação de $\mathrm{GA}_{3}$ proporcionou a produção de frutos sem sementes e não influenciou no teor de sólidos solúveis dos frutos de atemoieira 'Gefner'.

Termos para indexação: Annona squamosa x Annona cherimola, $\mathrm{GA}_{3}$, produção de frutos, regulador de crescimento.

\section{GIBBERELLIC ACID DOSES ON FRUIT SET AND FRUIT QUALITY OF ATEMOYA 'GEFNER'}

\begin{abstract}
The objective of present study was to evaluate the effect of gibberellic acid $\left(\mathrm{GA}_{3}\right)$ on the fruit set and fruit quality in atemoya 'Gefner' under irrigated conditions in the North of Minas Gerais. The experiment was performed in a commercial farm of atemoya 'Gefner'. The experimental design was completely randomized blocks with four replicates and five fruits per parcel. Five different doses of the commercial product Pro-Gibb ${ }^{\circledR},\left(10 \%\right.$ of $\left.\mathrm{GA}_{3}\right)$ in the form of soluble powder was used as follow: 0 (control), $250,500,750$ and $1000 \mathrm{mg} . \mathrm{L}^{-1}$. The product was applied directly on flowers at anthesis stage and more three applications were performed (7,21 and 35 days after anthesis stage). Fruit set, fruit length and fruit diameter were evaluated weekly during 19 weeks. After harvest the physical-chemical characteristics were submitted to analysis of variance and the effects of doses were tested and adjusted in regression equations. The percentage of fruit set, the fruit weight, pulp weight, the peel weight and $\mathrm{pH}$ increase with increasing of dose of $\mathrm{GA}_{3}$. The application of $\mathrm{GA}_{3}$ produces seedless fruit and does not affect the soluble solids content of atemoya 'Gefner' fruits.
\end{abstract}

Index terms: Annona squamosa x Annona cherimola, $\mathrm{GA}_{3}$, fructification, plant growth regulator.

\footnotetext{
${ }^{1}$ (Trabalho 117-13) - Recebido em: 14-03-2013. Aceito para publicação em: 05-07-2013. V Congresso Internacional \& Encontro Brasileiro sobre Annonaceae: do gene à exportação (19 a 23 de Agosto de 2013). Botucatu-SP. Apoio: Fapemig e Fazenda Simonica. ${ }^{2}$ Eng. Agrônomo, D.Sc., Professor do Departamento de Ciências Agrárias, Universidade Estadual de Montes Claros, Rua Reinaldo Viana, 2630, Bairro Bico da Pedra, Janaúba, Minas Gerais, CEP 39.440-000. E-mails: marlon.pereira@unimontes.br; silvia. nietsche@unimontes.br; gisele.mizobutsi@unimontes.br

${ }^{3}$ Graduandos em Agronomia, Universidade Estadual de Montes Claros, Rua Reinaldo Viana, 2630, Bairro Bico da Pedra, Janaúba, MG, CEP 39.440-000. E-mails: rayka.kristian@yahoo.com.br; fagner-edson07@hotmail.com
} 


\section{INTRODUÇÃO}

Pegamento de fruto pode ser definido pelo estádio de transição do ovário quiescente para um fruto jovem por meio de um rápido crescimento. Este fenômeno é considerado um dos mais importantes na reprodução sexual das plantas (JONG et al., 2009). Para a maioria das plantas, e em especial os membros da família Annonaceae, o pegamento dos frutos é influenciado pelas condições ambientais, em particular, as altas e baixas temperaturas e umidade relativa do ar, que podem afetar o desenvolvimento do grão de pólen e a deiscência da antera (BETTIOL NETO et al., 2009; PANDOLFINI, 2009).

A independência do desenvolvimento do fruto sem a fertilização (agamospermia) é considerada uma grande vantagem na horticultura, principalmente nos casos em que ocorre o baixo pegamento dos frutos, caso específico da atemoieira. Estudos conduzidos com este híbrido entre pinha (Annona squamosa L.) e cherimólia (Annona cherimola Mill.) apontam a baixa viabilidade polínica e níveis reduzidos de pegamento dos frutos (JALIKOP; KUMAR, 2007; MENDES et al., 2012). Entretanto, os frutos de atemoieira precisam ser polinizados artificialmente, utilizando-se mais recentemente do pólen da pinha que, apesar de se desenvolverem normalmente, têm a desvantagem de apresentar um grande número de sementes, além do alto custo associado à mão de obra da polinização artificial (PEREIRA et al., 2011).

A ausência de sementes nos frutos é uma das características mais apreciadas pelos consumidores, tanto para o consumo in natura (uva, banana e citros), como para o processamento (tomate) (GOURGET et al., 2005; KAPLAN, 2011). Além dos fenômenos biológicos da partenocarpia e da estenospermocarpia, frutos sem sementes podem ser obtidos por meio do tratamento das flores com diversos tipos de reguladores de crescimento, como as giberelinas, aplicados antes da polinização (VORAQUAX et al., 2000; PANDOLFINI, 2009).

As giberelinas são conhecidas pela habilidade de indução de pegamento de frutos e no incremento do tamanho celular (DORCEY et al., 2009; RAMEZANI; SHEKAFANDESH, 2009). As giberelinas são mais amplamente utilizadas comercialmente na viticultura, sendo as aplicações efetuadas desde o aparecimento da inflorescência até o início da maturação, visando, principalmente, ao aumento da produção através do aumento do peso dos cachos e das bagas e à obtenção de cachos medianamente soltos, que dispensam a operação de desbaste e facilitam o controle de doenças (KAPLAN, 2011). Além da videira, outras espécies, como a oliveira, citros, jambo e cherimólia, vêm sendo beneficiadas com a aplicação do ácido giberélico (RAMEZANI; SHEKAFANDEH, 2009; MONERUZZAMAN et al., 2011).

Embora algumas referências sobre a produção de frutos sem sementes estejam disponíveis na literatura, muito pouco se conhece sobre o pegamento e a frutificação efetiva de frutos de atemoieira por meio da aplicação de reguladores de crescimento. Portanto, não há uma recomendação precisa para incrementar a produção comercial de frutos paternocárpicos de atemoieira 'Gefner', cultivar que tem sido mais plantada no Brasil e também no exterior.

Diante do exposto, o objetivo do presente estudo foi avaliar o efeito da aplicação de ácido giberélico em diferentes doses no pegamento, frutificação efetiva e qualidade de frutos da atemoieira 'Gefner', nas condições irrigadas do norte de Minas Gerais.

\section{MATERIAL E MÉTODOS}

O experimento foi conduzido em pomar comercial de atemoieira 'Gefner', com plantas de 8 anos de idade, com espaçamento $4 \times 2 \mathrm{~m}$, latitude $15^{\circ} 05^{\prime} 39,5$ ' SE e longitude $43^{\circ} 47^{\prime} 43,9$ ' ' WO, no município de Matias Cardoso, na região do Jaíba-MG. O sistema de irrigação utilizado foi o de microaspersão.

O experimento foi instalado no dia 25 de abril de 2012, sendo selecionadas e identificadas 20 plantas de atemoieira 'Gefner', observando-se uniformidade, vigor e sanidade. $\mathrm{O}$ delineamento experimental foi o de blocos casualizados, com quatro repetições e 5 frutos por parcela, sendo que em cada planta foram aplicados todos os tratamentos.

O produto comercial utilizado no experimento foi o Pro-Gibb ${ }^{\circledR}$, composto por $10 \%$ de ácido giberélico $\left(\mathrm{GA}_{3}\right)$, na forma de pó solúvel. Como tratamentos, foram utilizadas 5 doses do produto: 0 (testemunha), 250; 500; 750 e $1.000 \mathrm{mg} . \mathrm{L}^{-1} \mathrm{GA}_{3}$. Cada dose do produto foi preparada com $250 \mathrm{~mL}$ de água, acrescentando-se $0,1 \%$ de espalhante adesivo não iônico SILWET L-77 Ag. A primeira aplicação da solução foi direcionada nas flores, no momento da antese, ou seja, flores em estádio fêmea ou funcionalmente pistiladas, efetuada por meio do uso do frasco com aplicador tipo "spray". As aplicações foram repetidas mais 3 vezes após o pegamento dos frutos, direcionadas nos próprios frutos, aos 7;21 e 35 dias após a antese.

Aos 7 dias após a primeira aplicação do ácido giberélico, no momento da antese, foi iniciada a avaliação do pegamento e da frutificação efetiva 
dos frutos, que foi seguido semanalmente. Foram avaliados também em campo o comprimento e o diâmetro dos frutos, a cada 14 dias, a partir de 7 dias após a antese. A colheita foi realizada na $19^{\mathrm{a}}$ semana, correspondendo a 133 dias após a aplicação da giberelina na antese, quando os frutos apresentavam o ponto de colheita com afastamento dos carpelos, coloração dos tecidos intercarpelares verdeamarelada e a cor da casca em verde mais claro. Os frutos de cada tratamento foram identificados, acondicionados em sacolas de papel, em seguida em caixas plásticas, e conduzidos ao laboratório de Pós-Colheita, localizado no Campus da Universidade Estadual de Montes Claros-UNIMONTES, no município de Janaúba-MG. Foram avaliados a massa fresca, o comprimento e o diâmetro dos frutos, ficando armazenados com temperatura constante de $25^{\circ} \mathrm{C}$ até a completa maturação.

Nos frutos maduros, foi avaliada a firmeza, utilizando o texturômetro da marca Brookfield modelo CT3 10K, medida em Newton, com o uso da ponteira com $4 \mathrm{~mm}$ de diâmetro. Em seguida, realizou-se a separação da casca, engaço, polpa e sementes, para a determinação de suas respectivas massas. Foi feita a contagem do número de sementes, quando encontradas, e uma alíquota de polpa dos frutos foi separada para a análise dos teores de sólidos solúveis, por refratometria, utilizando um refratômetro de bancada ATAGO. $\mathrm{O}$ pH foi medido em peagâmetro DIGIMED, modelo DM20, em amostras trituradas e homogeneizadas, as quais também foram usadas para a análise de acidez titulável, tendo seu resultado expresso em $\mathrm{mg}$ de ácido cítrico por $100 \mathrm{~g}$ de amostra.

As características avaliadas foram submetidas à análise de variância, e os efeitos das doses foram testados e ajustados em equações de regressão. Os modelos foram escolhidos com base na significância dos coeficientes de regressão, utilizando-se do teste de t, a $5 \%$ de probabilidade. O sistema SigmaPlot foi utilizado para ajustar algumas variáveis. As análises estatísticas foram efetuadas com uso do software estatístico SISVAR.

\section{RESULTADOS E DISCUSSÃO}

A porcentagem de pegamento dos frutos e da frutificação efetiva ao longo das 19 semanas após a antese foi decrescente, entretanto foi sempre maior considerando o incremento das doses de $\mathrm{GA}_{3}$ aplicadas (Figura 1). Não foi observado pegamento de frutos no tratamento-controle (com ausência da aplicação de $\mathrm{GA}_{3}$ ). A dose de $1.000 \mathrm{mg} \cdot \mathrm{L}^{-1} \mathrm{de}$
$\mathrm{GA}_{3}$ foi a que proporcionou a maior porcentagem de pegamento e frutificação efetiva ao longo das semanas, variando de $100 \%$ dos frutos da $1^{\text {a }}$ a $3^{\text {a }}$ semana, $95 \%$ da $4^{\mathrm{a}}$ à $6^{\mathrm{a}}$ semana, e na colheita, na $19^{\mathrm{a}}$ semana,estava com $85 \%$. Em relação aos demais tratamentos com $\mathrm{GA}_{3}$, as porcentagens de pegamento e frutificação efetiva foram inferiores, apresentando na $19^{\mathrm{a}}$ semana após a antese, no momento da colheita, $35 \%, 55 \%$ e $70 \%$ de frutificação efetiva nas doses de $250 \mathrm{mg} . \mathrm{L}^{-1}, 500 \mathrm{mg} . \mathrm{L}^{-1}$ e $750 \mathrm{mg} . \mathrm{L}^{-1}$ de $\mathrm{GA}_{3}$, respectivamente (Figura 1).

$\mathrm{O}$ aumento do pegamento dos frutos e da frutificação efetiva na maior dose do produto pode ser explicado devido a uma característica da giberelina de ser indutora da formação de enzimas proteolíticas, as quais podem liberar triptofano, precursor do ácido indolacético (AIA). Este fitormônio, por sua vez, regula quase todos os processos nas plantas, incluindo o pegamento e o desenvolvimento dos frutos (WANG et al., 2009).

As giberelinas são consideradas o segundo grupo de fitormônios que apresentam função essencial na coordenação do crescimento dos frutos e das sementes. Giberelinas ativas do tipo $\mathrm{GA}_{1}$ e $\mathrm{GA}_{3}$ são capazes de induzir pegamento de frutos e frutificação efetiva em várias espécies hortícolas (DORCEY et al., 2009). Diversos autores sugerem que a aplicação de giberelina exógena no momento da antese das flores, em alguns frutos, promove o alongamento celular do ovário e o desenvolvimento de frutos partenocárpicos, e já a giberelina produzida pelos grãos de pólen possuem a função de incrementar a produção de auxina no ovário, a qual serve como um sinal para a fixação dos frutos (SRIVASTAVA \& HANDA, 2005).

Estudo conduzido por Mota Filho et al (2012) demonstrou que o uso de auxinas sintéticas (ácido indolacético, ácido naftalenoacético, ácido indolbutírico e o diclorofenoxiacético), em diferentes doses, não foram eficientes, promovendo baixos índices de pegamento de frutos em atemoieira 'Gefner'. Em contrapartida, Pereira et al. (2012), ao aplicarem 1.000 ppm de $\mathrm{GA}_{3}$ na atemoia 'Gefner' plantada no estado da Flórida, EUA, sem polinização artificial, observaram frutificação efetiva acima de $80 \%$, até o momento da colheita dos frutos, na $15^{\mathrm{a}}$ semana após a antese. Estes resultados demonstram o potencial superior do uso do $\mathrm{GA}_{3}$, com destaque para a dose de $1.000 \mathrm{mg} \cdot \mathrm{L}^{-1}$ de GA${ }_{3}$, em substituição à polinização artificial, e à aplicação de auxinas sintéticas, devido à elevada fixação de frutos observada.

A falta de pegamento dos frutos na testemunha pode ser explicada devido à ausência de um 
sinalizador para fixação dos frutos na planta, já que não foi realizada a polinização, não sendo possível o desenvolvimento da semente, que seria uma fonte de auxina necessária para promover a fixação dos frutos. Como nestes frutos da testemunha (controle) não houve aplicação de giberelina exógena, é provável que a produção de auxina tenha sido direta ou indiretamente comprometida, ocasionando a consequente abscisão dos frutos.

As massas do fruto, polpa e casca ajustaramse ao modelo racional de regressão não linear (Figura 2). Observou-se que a massa do fruto incrementou de acordo com o aumento da dose de $\mathrm{GA}_{3}$ aplicada, demonstrando, na dose de $1.000 \mathrm{mg} . \mathrm{L}^{-1}$, o valor máximo, com média de 196,49 g. A massa da polpa seguiu o mesmo efeito, tendo na dose de $1.000 \mathrm{mg} . \mathrm{L}^{-}$ ${ }^{1}$ o seu valor máximo, com média de $91,21 \mathrm{~g}$, assim como a massa da casca, que seguiu o mesmo padrão, tendo o valor máximo com média de $78,38 \mathrm{~g}$ na dose de $1.000 \mathrm{mg} \cdot \mathrm{L}^{-1}$. De acordo com as tendências dos gráficos, observa-se que, em futuros trabalhos, podem ser testadas maiores dosagens para atemoia, já que, conforme resultados obtidos por Yonemoto et al. (2004) em cherimólia utilizando $1.600 \mathrm{mg} . \mathrm{L}^{-1}$, foram obtidos frutos com mais de $300 \mathrm{~g}$. São encontradas diversas recomendações na literatura acerca da concentração do ácido giberélico a ser aplicado, variando de 40 a $400 \mathrm{mg} . \mathrm{L}^{-1}$ para videira e de $20 \mathrm{a}$ $100 \mathrm{mg} . \mathrm{L}^{-1}$ para o jambo (CASANOVA et al., 2009; MONERUZZAMAN et al., 2011). Em oliveiras, a aplicação de ácido giberélico a $30 \mathrm{mg} . \mathrm{L}^{-1}$ acelerou o crescimento do fruto, peso do fruto e produção total (RAMEZANI; SHEKAFANDEH, 2009). É de consenso que as dosagens são fortemente afetadas pelas condições ambientais, genótipo e estação do ano (CASANOVA et al., 2009). A dosagem deve ser definida de acordo com a espécie e a cultivar.

Segundo Jong et al. (2009), o crescimento de órgãos vegetais promovidos por giberelinas deve-se principalmente a um aumento do volume das células já existentes ou recentemente divididas. Entretanto, frutos sem sementes obtidos via aplicação de ácido giberélico são geralmente menores que os frutos com semente formados a partir da polinização natural ou artificial.

A porcentagem de polpa e casca ajustaram-se ao modelo quadrático da regressão. Ambas na dose $796,96 \mathrm{mg} . \mathrm{L}^{-1}$ tiveram seu melhor ponto, porém com efeito contrário, sendo a porcentagem de polpa com $60 \%$ seu maior valor, e a casca com $40 \%$, seu menor valor (Figura 3). De forma geral, constatou-se que as menores doses proporcionam menor porcentagem de polpa e maior porcentagem de casca no fruto, e com o aumento das doses ocorre o inverso. Para o consumidor, quanto maior a porcentagem de polpa e menor a porcentagem de casca é mais interessante. Entretanto, os valores de casca do presente trabalho foram superiores aos relatados na literatura para frutos com sementes. Jong et al. (2009) relatam que, embora o volume de frutos induzidos com aplicação de $\mathrm{GA}_{3}$ seja pequeno, a espessura do pericarpo é comparável a frutos com sementes. Além disso, esse pericarpo de frutos com aplicação de $\mathrm{GA}_{3}$ possui menor quantidade de células, mas com maior volume celular do que frutos com sementes.

$\mathrm{O} \mathrm{pH}$ da polpa dos frutos demonstrou incremento linear com o aumento nas doses de $\mathrm{GA}_{3}$, que iniciou em 4,83 na dose de $250 \mathrm{mg} . \mathrm{L}^{-1}$ e atingiu 5,37 na dose de $1.000 \mathrm{mg} . \mathrm{L}^{-1}$ (Figura 4). Segundo Leiser (2006), além dos meristemas e folhas jovens, a produção de auxinas também é detectada nas sementes, e este regulador participa ativamente no processo de crescimento do fruto por meio do incremento da divisão celular. No presente trabalho, foi observada uma redução significativa no número de sementes; desta forma, sem a presença de sementes, possivelmente pode ter ocorrido redução na produção de auxina promovendo em contrapartida um incremento no potencial hidrogeniônico.

As características comprimento, diâmetro, massa de sementes, número de sementes, percentagem de sementes, acidez titulável, teor de sólidos solúveis e firmeza não apresentaram diferenças significativas entre as doses de $\mathrm{GA}_{3}$ a $5 \%$ de probabilidade, pelo teste de F. Os frutos apresentaram, em média, $6,53 \mathrm{~cm}$ de comprimento e $4,93 \mathrm{~cm}$ de diâmetro, dimensões menores que as encontradas por Pereira et al. (2012) em frutos advindos da polinização artificial, com $10,3 \mathrm{~cm}$ de comprimento e $8,7 \mathrm{~cm}$ de diâmetro. Com relação às análises de sementes nos frutos, embora prevista, já que as flores não foram ensacadas na antese, com possibilidade de polinização natural por pequenos coleópteros, foi observada a produção de frutos sem sementes ou partenocárpicos. Segundo Pereira et al. (2012), estudando atemoieira 'Gefner' na Flórida, a aplicação de 1.000 ppm de $\mathrm{GA}_{3}$ sem polinização artificial proporcionou frutos sem sementes, e esta mesma dose aplicada em frutos polinizados resultou em menor relação número de sementes por $100 \mathrm{~g}$ de fruto e polpa quando comparado às menores doses testadas.

A polpa dos frutos apresentou acidez titulável média de $0,16 \mathrm{mg}$ ácido cítrico/100 g polpa e teor de sólidos solúveis de $18,24^{\circ}$ Brix. Em média, os frutos demonstraram firmeza de 6,39 N. Pereira et al. (2012) também não verificaram diferenças significativas no teor de sólidos solúveis de frutos de atemoia 'Gefner' testando doses de $\mathrm{GA}_{3}$, no entanto 
obtiveram média de $24,4^{\circ}$ Brix, valor superior ao do presente trabalho. Essa alteração possivelmente se deve à diferenças nas condições edafoclimáticas e de manejo cultural de cada local. Apesar disso, os frutos do presente trabalho com menores valores apresentaram sabor agradável para consumo. Casanova et al. (2009), trabalhando com variedades de uva sem semente, demonstraram o efeito da aplicação do ácido giberélico no incremento, no conteúdo total de açúcares e no conteúdo total de água. Estes resultados demonstram o efeito do $\mathrm{GA}_{3}$ em não interferir negativamente sobre o teor de sólidos solúveis e interferindo positivamente sobre o acúmulo de açúcares e água em frutos.

Foi observado no presente trabalho uma deformação de $27 \%$ dos frutos da atemoieira 'Gefner' com aplicação do ácido giberélico, principalmente com pequeno anelamento na região central do fruto. Pereira et al. (2002) também observaram desuniformidade no formato de frutos de pinha com polinização artificial, nos horários de 5; 6 e 7 horas, com valor de $6 \%, 11 \%$ e $7 \%$, respectivamente.
Normalmente, a deformidade de frutos polinizados ocorre devido a algum problema com a efetiva deposição de grãos de pólen no estigma, seguido da posterior não formação das sementes em partes do fruto. No presente experimento, a irregularidade do formato dos frutos ocorreu, provavelmente, em função da ausência de sementes e polpa em algumas partes dos frutos e consequente atrofia dos carpelos, alterando a forma natural destes, semelhante a um cone. Este fato não é interessante comercialmente depreciando os frutos; portanto, novos estudos devem ser realizados para minimizar este problema.

De acordo com Jong et al. (2009), os frutos induzidos por meio do uso de giberelinas são menores e de formato mais irregular quando comparados com frutos tratados com auxinas. Serrani et al. (2007) relataram a importância da indução de frutos via aplicação combinada de giberelinas e auxinas. Os autores apoiam a hipótese de que as atividades de elongação celular e divisão celular são atividades cocoordenadas e dirigidas por um delicado balanço entre os dois fitormônios.

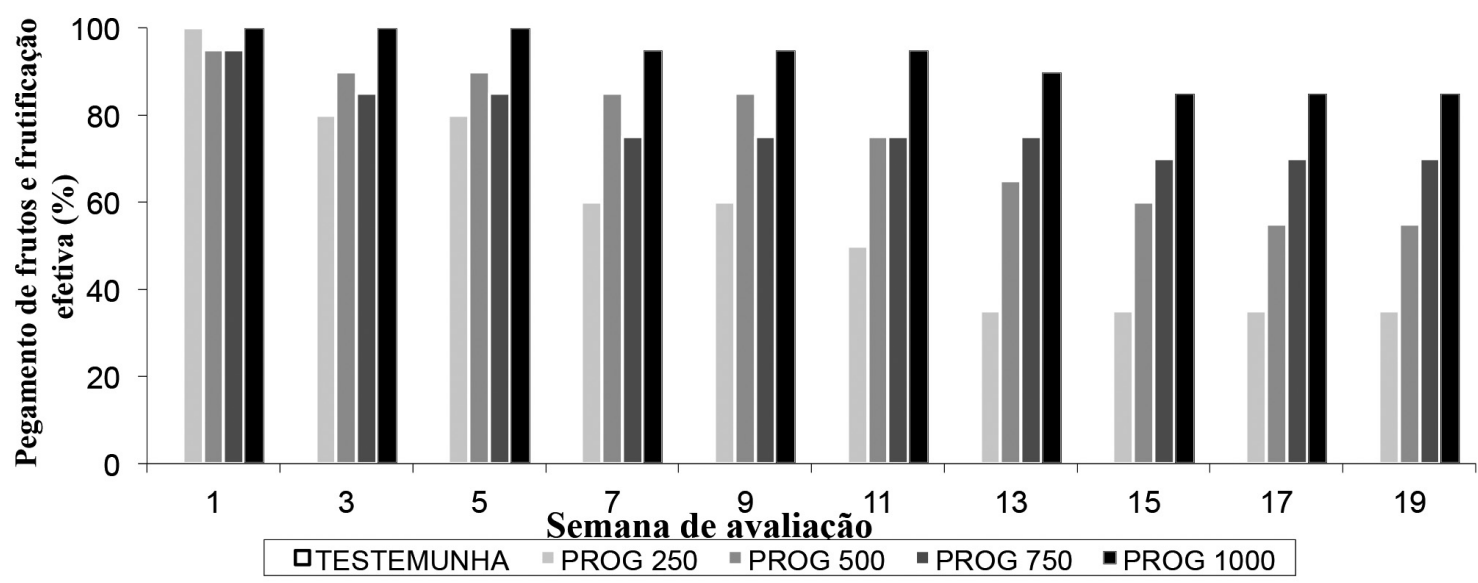

FIGURA 1 - Porcentagem de pegamento de frutos e frutificação efetiva de atemoieira 'Gefner', submetida a diferentes doses de $\mathrm{GA}_{3}\left(\mathrm{mg} . \mathrm{L}^{-1}\right)$, no município de Matias Cardoso, norte de Minas Gerais. 

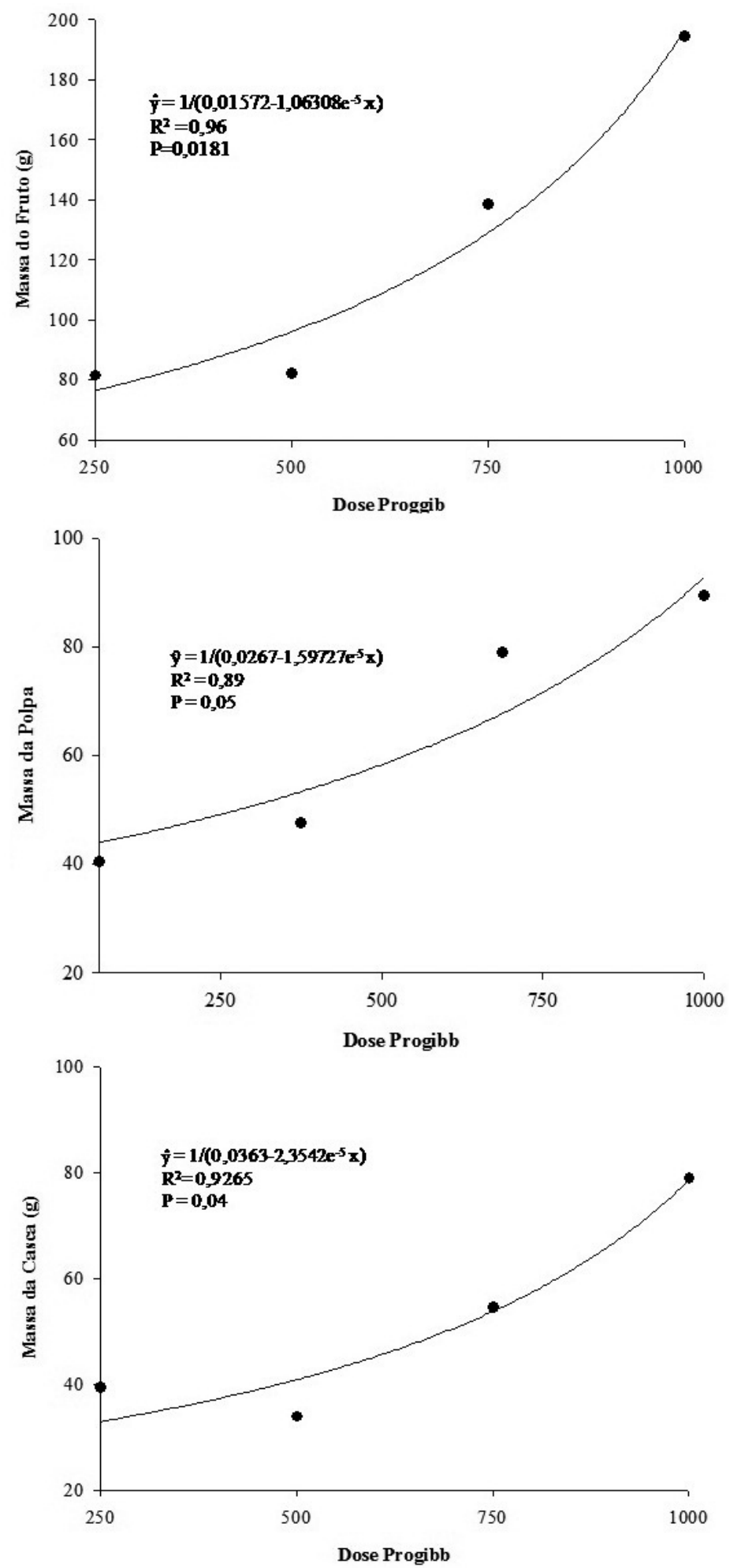

FIGURA 2 - Massa fresca do fruto, da polpa e da casca do fruto de atemoieira 'Gefner', submetida a diferentes doses de $\mathrm{GA}_{3}\left(\mathrm{mg} . \mathrm{L}^{-1}\right)$, no município de Matias Cardoso, norte de Minas Gerais. 


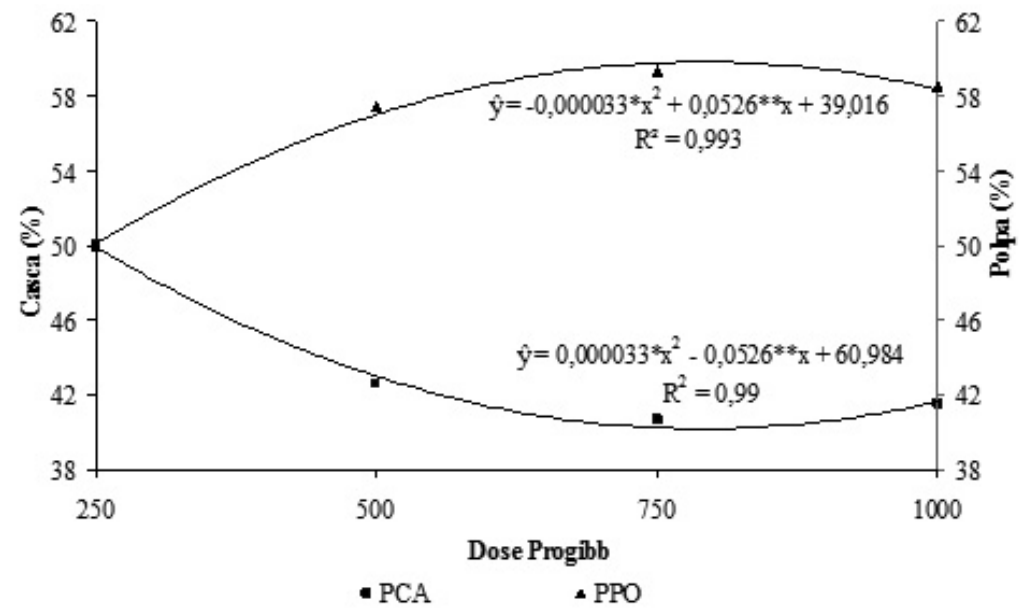

FIGURA 3 - Porcentagem de casca (PCA) e polpa (PPO) de frutos de atemoieira 'Gefner', submetida a diferentes doses de $\mathrm{GA}_{3}\left(\mathrm{mg} . \mathrm{L}^{-1}\right)$, no município de Matias Cardoso, norte de Minas Gerais.

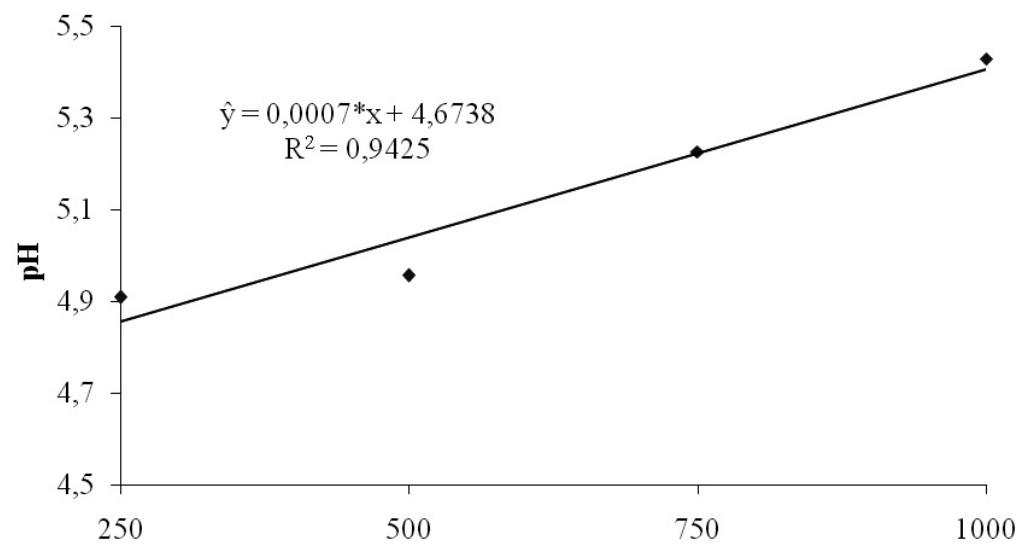

Dose Progibb

FIGURA 4 - Valor de pH da polpa de frutos de atemoieira 'Gefner', submetida a diferentes doses de $\mathrm{GA}_{3}$ (mg.L-1 ${ }^{-1}$, no município de Matias Cardoso, norte de Minas Gerais.

\section{CONCLUSÕES}

A aplicação de $1.000 \mathrm{mg} . \mathrm{L}^{-1}$ de $\mathrm{GA}_{3}$ proporciona elevada produção de frutos de atemoieira 'Gefner' sem sementes com sabor agradável, porém com certa desuniformidade no formato.

\section{REFERÊNCIAS}

BETTIOL NETO, J.E.; DEL NERO, M.; KAVATI, R.; PINTO-MAGLIO, C.A.F. Viabilidade e conservação de pólen de três Anonas comerciais. Bragantia, Campinas, v.68, p. 825-837, 2009.
CASANOVA, L.; CASANOVA, R.; MORET, A.; AUGUSTI, M. the application of gibberellic acid increases berry size of "Emperatriz" seedless grape. Spanish Journal Agricultural Research, Madri, v. 7, p.919-927, 2009.

DORCEY, E.; URBEZ, C.; BLAZQUEZ, M.A.; CARBONELL, J.; PEREZ-AMADOR, A. Fertilization-dependent auxin response in ovules triggers fruit development through modulation of gibberellin metabolism in Arabidopsis. Plant Journal, Oxford, v.58, p.318-332, 2009.

GOURGET, B.; VAN HEUSDEN, A.W.; LINDHOUT, P. Pathernocarpic fruit development in tomato. Plant Biology, Stuttgart, v.7, p.131-139, 2005. 
JALIKOP, S.H.; KUMAR, R. Pseudo-xenic effect of allied Annona spp. pollen in hand pollination of cv. 'Arka Sahan' [(A.cherimola $\times$ X A. squamosa $) \cdot A$. squamosa]. HortScience, Alexandria, v.42, p.1.5341.538, 2007.

JONG, M.; MARIANI, C.; VRIEZEN, W.H. The role of auxin and gibberellin in tomato fruit set. Journal of Experimental Botany, Oxford, v.60, p. 1.523-1.532, 2009.

KAPLAN, M. The effect of the method of application of growth regulators on fruit quality of 'Einset seedless' grape (Vitis sp. L.). Acta Agrobotanica, Lublin, v.64, p. 189-196, 2011.

LEISER, O. Dynamic integration of auxin transport and signalling. Current Biology, London, v.16, p.424-433, 2006.

MENDES, H.T.A.; COSTA, M.R.; NIETSCHE, S.; OLIVEIRA, J.A.A.; PEREIRA, M.C.T.Pollen grain germination and fruit set in 'Brazilian seedless' sugar apple (Annona squamosa L). Crop Breeding and Applied Biotechnology, Viçosa, MG, v.12, p.277280, 2012.

MONERUZZAMAN, K.M.; HOSSAIN, A.B.M.S.; NORMANIZA, O.; BOYCE, A.N. Growth, yield and quality responses to gibberellic acid $\left(\mathrm{GA}_{3}\right)$ of Wax apple Syzygium samarangense var. Jambu air madu fruits grown under field condition. African Journal of Biotechnology, Lagos, v.10, p. 1.19111.1918, 2011.

MOTA FILHO, V.J.G.; PEREIRA, M.C.T.; NIETSCHE, S.; GUIMARÃES, J.F.R.; MOREIRA, G.B.R.; FERNANDES, T.P. Uso de fitorreguladores no desenvolvimento de frutos de atemoieira (Annona cherimola x Annona squamosa cv. Gefner). Revista Ceres, Viçosa, MG, v.56, p.636-645, 2012.

PANDOLFINI, T. Seedless fruit production by hormonal regulation of fruit set. Nutrients, Basel, v.1, p.168-177, 2009.

PEREIRA, M.C.T.; CRANE, J.H.; NIETSCHE,S.; MONTAS, W. Uso do ácido giberélico e polinização artificial no pegamento e qualidade de frutos da atemoieira 'Gefner'. In: CONGRESSO BRASILEIRO DE FRUTICULTURA, 2012, Bento Gonçalves. Anais... CD-ROM.
PEREIRA, M.C.T.; NIETSCHE,S.; COSTA, M.R.; CRANE, J.H.; CORSATO, C.D.A.; MIZOBUTSI, E.H. Anonáceas: pinha, atemoia e graviola . Informe Agropecuário, Belo Horizonte, v.32, n.264, p.2634, 2011.

PEREIRA, M.C.T.; NIETSCHE, S.; SANTOS, F.S.; XAVIER, A.A.; CUNHA, L.M.; NUNES, C.F.; SANTOS, F.A. Efeito de horários de polinização artificial no pegamento e qualidade de frutos de pinha (Annona squamosa L.). Revista Brasileira de Fruticultura, Jaboticabal, v. 25, n. 2, p. 203205. 2002.

RAMEZANI, S.; SHEKAFANDEH, A. Roles of gibberellic acid and zinc sulphate in increasing size and weight of olive fruit. African Journal of Biotechnology, Lagos, v.8, p.6.791-6.794, 2009.

SERRANI, J.C.; SANJUAN, R.; RUIZ-RIVERO, O.; FOS, M.; GARCIA-MARTINEZ, J.L. Gibberellin regulation of fruit set and growth in tomato. Plant Physiology, Rockville, v.145, p.246-257, 2007.

SRIVASTAVA, A.; HANDA, A. K. Hormonal regulation of tomato fruit development: a molecular perspective. Journal of Plant Growth Regulators, Berlin, v. 24, p.67-82, 2005.

VORAQUAUX, F.; BLANVILLAIN, R.; DELSENY, M.; GALLOIS, P. Less is better: new approaches for seedless fruit production. Trends in Biotechnology, Cambridge, v.18, p. 235-242, 2000.

WANG, H.; SCHAUER, N.; USADEL, B.; FRASSE, P.; ZOUINE, M.; HERNOULD, M.; LATCHÉ, A.; PECH, J.C.; FERNIE, A.R.; BOUZAYEN, M. Regulatory features underlying pollinationdependent and independent tomato fruit set revealed by transcript and primary metabolite profiling. Plant Cell, Rockville,v. 21, p. 1.428-1.452, 2009.

YONEMOTO,Y.; KOURA., S.; HASEGAWA, K.; YAMAMOTO. K. Fruit set and fruit growth of seedless Cherimoya( Annona Cherimola Mill.) induced by $\mathrm{GA}_{3}$ under greenhouse cultivation in Japan. Acta Horticulture, Leuven, v. 653, p.63- 66. 2004. 